\title{
Desempenho de híbridos de couve-flor de verão em Jaboticabal
}

\author{
Beatriz Cristina B de Almeida Monteiro; Hamilton César de O Charlo; Leila T Braz \\ UNESP-FCAV, Depto. Prod. Vegetal, Rod. Prof. Paulo Donato Castellane s/n, 14884-900 Jaboticabal-SP; hamiltoncharlo@gmail.com
}

\begin{abstract}
RESUMO
Instalou-se um experimento, em campo aberto, com o objetivo de comparar o desempenho de oito híbridos de couve-flor de verão. Adotou-se o delineamento em blocos casualizados, com oito tratamentos e quatro repetições. A parcela experimental de $14 \mathrm{~m}^{2}$ constou de 28 plantas distribuídas no espaçamento de 1,0 m entre linhas e $0,5 \mathrm{~m}$ entre plantas. Foram avaliados os híbridos de couve-flor: TPX00123, TPC00218, Sarah AF-1169, Sharon, Snow-Flake, FirstSnow, Veneza e Verona. As adubações de cobertura foram realizadas com $10,5 \mathrm{~kg}$ de sulfato de amônio e $2,8 \mathrm{~kg}$ de cloreto de potássio, aplicados aos 15, 30, 45 e 60 dias após o transplante das mudas. A colheita das cabeças foi realizada quando começaram a atingir o ponto ideal de colheita com cabeças compactas e botões florais ainda unidos. Os híbridos TPC00218 e TPX00123 mostraram-se promissores, com produtividades comerciais de 23,8 e 23,2 t ha ${ }^{-1}$, respectivamente. O híbrido First-Snow possui baixo desenvolvimento de plantas e boa produtividade, podendo ser cultivado mais adensado. O híbrido Snow-Flake foi o que obteve menor produtividade, não sendo recomendado para plantio na região de Jaboticabal. Todos os híbridos testados apresentaram produção classificada na categoria extra e na classe 8 (maiores que $230 \mathrm{~mm}$ ).
\end{abstract}

Palavras-chave: Brassica oleracea var. botrytis, adaptabilidade, produtividade.

\begin{abstract}
Performance of hybrids of cauliflower for summer season, in Jaboticabal, Brazil

The experiment was installed in field and aimed to compare the performance of eight hybrids of summer cauliflower. The statistical design was the randomized blocks with eight treatments and four replicates. The experimental plot measured $14 \mathrm{~m}^{2}$, with 28 plants of cauliflower spacing $1.0 \mathrm{~m}$ between rows and $0.5 \mathrm{~m}$ between plants. It was considered for evaluation 10 plants of the two central rows of each plot and the following hybrids of cauliflower: TPX00123, TPC00218, Sarah AF-1169, Sharon, Snow-Flake, First-Snow, Veneza and Verona. Top-dressing was carried out with $10,5 \mathrm{~kg}$ of ammonium sulfate and $2,8 \mathrm{~kg}$ of potassium chloride, applied at 15,30, 45 and 60 days after the seedlings transplantation. The cauliflowers were harvested at the ideal moment, with compact heads and united flower buds. The hybrids TPC00218 and TPX00123 were promising, with commercial productivity of 23.8 and $23.2 \mathrm{t} \mathrm{ha}^{-1}$, respectively. The hybrid First-Snow presented low plant development and good productivity, so it can be cultivated with smaller spacing among plants. The hybrid Snow-Flake presented the lowest productivity, so it is not recommended for the region of Jaboticabal. All tested hybrids had its production classified as "extra" and class 8 (greater than $230 \mathrm{~mm}$ ).
\end{abstract}

Keywords: Brassica oleracea var. botrytis, adaptability, productivity.

(Recebido para publicação em 25 de setembro de 2008; aceito em 10 de dezembro de 2009) (Received on September 25, 2008; accepted on December 10, 2009)

\begin{abstract}
$\mathrm{A}$ produção de hortaliças pode gerar retornos econômicos e terapêuticos, porém, exige um intenso envolvimento de capital, trabalho qualificado e conhecimentos. É uma atividade que integra o agronegócio e envolve diversos setores da cadeia produtiva, devendo-se produzir com preços competitivos, alta qualidade e constância (Fontes, 2005).

No estado de São Paulo, a couveflor está entre as quinze hortaliças mais produzidas (May et al., 2007), portanto, o seu valor econômico é bastante expressivo. Essa olerícola tem grande importância, particularmente, para os agricultores familiares que, em geral, cultivam pequenas áreas ao longo do ano. Nesse caso, o fato de ser bastante exigente em mão-de-obra, principalmente, na fase de colheita, não se constitui embaraço,
\end{abstract}

sendo considerada uma cultura lucrativa (May et al., 2007).

A couve-flor é uma planta exigente em relação às condições climáticas, sendo originária de regiões de clima temperado ameno e bienal. Devido a essa exigência em baixa temperatura, seu cultivo era restrito a regiões de temperaturas mais amenas (Blanco et al., 1997). Mais recentemente, através do melhoramento genético houve desenvolvimento de híbridos de couve-flor que podem ser cultivados em condições de clima mais quente, permitindo a produção durante todo o ano (Filgueira, 2003). Entretanto, a sensibilidade das cultivares à temperatura é bastante variável. Desse modo, estudos relacionados a tolerância das novas cultivares às condições das diferentes regiões, são importantes sob pena do olericultor não obter colheita ou produto adequado às necessidades do mercado.

O plantio de cultivares de inverno em condições de alta temperatura pode ocasionar o não florescimento da planta, ou cabeças semivegetativas, de coloração esverdeada e intercalada por folíolos, impróprias para comercialização. Segundo Freitas (1995), é de grande importância a escolha de cultivares adaptadas às diferentes condições de cultivo, que apresentem produtividade elevada, qualidade e ainda que ofereçam baixo custo de produção, considerando a duração do ciclo produtivo específico de cada uma.

Assim, o presente trabalho teve por objetivo avaliar o desempenho de híbridos de couve-flor de verão, em 
Jaboticabal - SP.

\section{MATERIAL E MÉTODOS}

O experimento foi conduzido entre 01/02/07 e 03/06/07, no Câmpus de Jaboticabal da UNESP, cujas coordenadas geográficas são $21^{\circ} 14^{\prime} 05^{\prime \prime}$ Latitude Sul, $48^{\circ} 17^{\prime}$ 09" Longitude Oeste e altitude de $614 \mathrm{~m}$. O clima, segundo a classificação de Köppen, é do tipo Aw com transição para Cwa (VOLPE $\left.{ }^{1}\right)$. O solo da área experimental é do tipo, (LR) Latossolo Roxo Eutrófico, A moderado, textura muito argilosa, caulinítico, hipoférrico, relevo suave ondulado ou ondulado (Andrioli \& Centurion, 1999).

$\mathrm{O}$ delineamento experimental adotado foi de blocos casualizados, com oito tratamentos (híbridos) e quatro repetições. Os tratamentos foram representados por oito híbridos de couve-flor (TPX00123 e TPC00218 (Agristar do Brasil); Sarah AF-1169 e Sharon (Sakata Seed Sudamerica); Snow-Flake e FirstSnow (ISLA Sementes); Veneza e Verona (Seminis)). A parcela experimental tinha $14 \mathrm{~m}^{2}$, constando de 28 plantas de couve-flor distribuídas no espaçamento definido de $1,0 \mathrm{~m}$ entre linhas e $0,5 \mathrm{~m}$ entre plantas. Foram consideradas para avaliação 10 plantas das duas linhas centrais de cada parcela.

Para a instalação do experimento, o solo foi amostrado na profundidade de 0-0,20 m. Sua análise química revelou: $\mathrm{pH}$ em $\mathrm{C}_{\mathrm{a}} \mathrm{Cl}_{2}=5,3 ; \mathrm{MO}=18,0 \mathrm{~g} \mathrm{dm}^{-3}$; P-resina $=64,0 \mathrm{mg} \mathrm{dm}^{-3} ; \mathrm{K}=3,1 \mathrm{mmol}_{\mathrm{c}}$ $\mathrm{dm}^{-3} ; \mathrm{Ca}=62,0 \mathrm{mmol}_{\mathrm{c}} \mathrm{dm}^{-3} ; \mathrm{Mg}=30,0$ $\mathrm{mmol}_{\mathrm{c}} \mathrm{dm}^{-3} ; \mathrm{H}+\mathrm{Al}=22,0 \mathrm{mmol}_{\mathrm{c}} \mathrm{dm}^{-3}$; $\mathrm{SB}=70,1 \mathrm{mmol}_{\mathrm{c}} \mathrm{dm}^{-3} ; \mathrm{T}=99,6 \mathrm{mmol}_{\mathrm{c}}$ $\mathrm{dm}^{-3} ; \mathrm{V} \%=67$. Com base na análise da fertilidade do solo e na recomendação de Trani \& Raij (1997), procedeu-se a correção do solo com calcário para elevar a saturação de bases (V\%) a $80 \%$ e o teor de magnésio a um mínimo de 9 $\mathrm{mmol} \cdot \mathrm{dm}^{-3}$. O calcário foi aplicado em área total e incorporado por meio de aração e gradagem.

A adubação de plantio, também de acordo com Trani \& Raij (1997), correspondeu à aplicação de $300 \mathrm{~kg}$ ha ${ }^{-1}$ de sulfato de amônio, $1100 \mathrm{~kg} \mathrm{ha}^{-1}$ superfosfato simples, $215 \mathrm{~kg} \mathrm{ha}^{-1}$ cloreto de potássio, e $3 \mathrm{~kg} \mathrm{ha}^{-1} \mathrm{de} \mathrm{B}$, como fonte Bórax, em solo anteriormente preparado (aração e gradagem).

As adubações de cobertura foram feitas de acordo com as doses recomendadas por Trani \& Raij (1997), equivalentes a $600 \mathrm{~kg} \mathrm{ha}^{-1}$ de sulfato de amônio misturado a $160 \mathrm{~kg} \mathrm{ha}^{-1}$ de cloreto de potássio, o que correspondeu a aproximadamente 9,5 $\mathrm{g}_{\text {planta }}{ }^{-1}$ da mistura. Foi aplicado 2,4 $\mathrm{g}$ da mistura aos $15,30,45$ e 60 dias após o transplantio das mudas.

Para a formação das mudas, utilizouse o sistema de semeadura em bandejas. As sementes dos híbridos de couveflor foram semeadas em 01/02/07 em bandejas de poliestireno expandido, com capacidade para 128 células, com substrato Plantmax Hortaliças ${ }^{\circledR}$, colocando-se uma semente por célula, sendo a irrigação feita automaticamente por microaspersão.

O transplante foi realizado aos 37 dias após a semeadura, quando as plântulas apresentavam quatro a cinco folhas definitivas. Para o controle de pragas e doenças foram utilizados inseticidas e fungicidas recomendados para a cultura, de acordo com a ocorrência do agente, inseto ou patógeno na área experimental, adotando-se a dose recomendada pelo fabricante.

O controle de plantas invasoras foi feito com capina manual. As irrigações foram feitas durante todo o ciclo da cultura e em complementação às chuvas. Utilizou-se o sistema de aspersão convencional.

A colheita foi realizada à medida que as cabeças começaram a atingir o ponto ideal de colheita, isto é, cabeças compactas com botões florais ainda unidos. Iniciou aos 91 dias após a semeadura e se estendeu por mais 30 dias. As plantas centrais de cada parcela foram mensuradas ainda em campo, antes da colheita, quanto ao diâmetro da planta na linha e na entrelinha $(\mathrm{cm})$ e precocidade média (dias da semeadura até a colheita). Após a colheita, foram levadas ao laboratório para avaliações de massa (g), altura $(\mathrm{cm})$, diâmetro $(\mathrm{cm})$ e diâmetro do caule (cm) e calculada a produtividade média estimada por hectare $\left(\mathrm{kg} \mathrm{ha}^{-1}\right)$.

A classificação das cabeças foi feita por tamanho e qualidade ( Programa Horti \& Fruti Padrão, 1999), Para esta classificação observaram-se os parâmetros de classificação por diâmetro transversal das inflorescências, com oito classes de produto e classificação por qualidade ou categoria da couveflor sendo mensurada pela ocorrência de defeitos graves e leves, associados à tonalidade de coloração.

Para a caracterização da tonalidade considerou-se a variação da coloração, sendo a branca caracterizada pela predominância absoluta da cor branca, a creme pela coloração creme, em qualquer proporção e a amarela pela cor amarela, em qualquer proporção. As tonalidades de inflorescências usadas na classificação comercial de couve-flor para definição do tipo ou categoria foram as cores branca, creme e amarela.

Os dados obtidos foram submetidos à análise de variância (teste F) e as médias comparadas pelo teste de Tukey, segundo o delineamento proposto, utilizando-se o programa estatístico Estat (UNESP, Jaboticabal-SP).

\section{RESULTADOS E DISCUSSÃO}

Na Tabela 1, são apresentadas as médias do diâmetro da planta na linha, diâmetro da planta na entrelinha, diâmetro do caule e precocidade média de oito híbridos de couve-flor de verão. Para todas as características avaliadas, foram observadas diferenças estatísticas significativas entre os híbridos avaliados.

Para o diâmetro da planta na linha verificou-se que os híbridos Verona e Sharon apresentaram as maiores médias para esta característica, com 97,07 e $95,30 \mathrm{~cm}$, respectivamente, não diferindo estatisticamente apenas do híbrido TPX $00123(88,40 \mathrm{~cm})$. Observa-se que estes híbridos tiveram maior desenvolvimento e que o espaçamento adotado de $50 \mathrm{~cm}$ entre plantas pode ter sido insuficiente para que as cultivares expressassem seu potencial produtivo, pois pode ter ocorrido competição entre as 
Tabela 1. Médias do diâmetro da planta na linha (DPL), diâmetro da planta na entrelinha (DPT), diâmetro do caule (DC) e precocidade média (PM) de oito híbridos de couve-flor de verão (means of diameter of plants in the row, diameter of plants in inter-row, diameter of stem and mean precocity in eight hybrids of Summer cauliflower). Jaboticabal, UNESP, 2007.

\begin{tabular}{llclc}
\hline Híbridos & DPL $(\mathbf{c m})$ & DPT $(\mathbf{c m})$ & DC $(\mathbf{c m})$ & PM (dias) \\
\hline Snow-Flake & $71,37 \mathrm{~cd}$ & $90,55 \mathrm{e}$ & $2,81 \mathrm{~b}$ & $95,00 \mathrm{~d}$ \\
First-Snow & $67,40 \mathrm{~d}$ & $97,75 \mathrm{de}$ & $2,99 \mathrm{ab}$ & $107,00 \mathrm{c}$ \\
TPX 00123 & $88,40 \mathrm{ab}$ & $111,17 \mathrm{ab}$ & $3,09 \mathrm{a}$ & $111,00 \mathrm{bc}$ \\
TPC 00218 & $80,71 \mathrm{bc}$ & $106,40 \mathrm{bcd}$ & $2,89 \mathrm{ab}$ & $109,00 \mathrm{c}$ \\
Sharon & $95,30 \mathrm{a}$ & $115,40 \mathrm{a}$ & $2,97 \mathrm{ab}$ & $116,00 \mathrm{ab}$ \\
Veneza & $80,82 \mathrm{bc}$ & $107,90 \mathrm{abc}$ & $3,09 \mathrm{a}$ & $108,00 \mathrm{c}$ \\
Verona & $97,07 \mathrm{a}$ & $112,77 \mathrm{ab}$ & $3,07 \mathrm{ab}$ & $119,00 \mathrm{a}$ \\
Sarah & $71,50 \mathrm{~cd}$ & $99,40 \mathrm{cde}$ & $2,82 \mathrm{~b}$ & $108,00 \mathrm{c}$ \\
\hline Teste F & $22,43 * *$ & $20,46 * *$ & $4,17 * *$ & $36,09 * *$ \\
\hline DMS (Tukey, 5\%) & 11,2496 & 8,9497 & 0,2701 & 5,6231 \\
\hline CV (\%) & 5,81 & 3,59 & 3,84 & 2,17 \\
\hline
\end{tabular}

Médias seguidas pela mesma letra na coluna não diferem entre si, pelo Teste de Tukey, a 5\% de probabilidade (means followed by the same letter in the column don't differ significantly, according to Tukey's test at $5 \%$ level of probability).

plantas por luz, e/ou nutrientes.

Observou-se no híbrido First-Snow o menor diâmetro da planta na linha, o qual não diferiu estatisticamente dos híbridos Snow-Flake e Sarah. Estes híbridos apresentam plantas mais compactas, o que é altamente desejável, pois pode-se adensar o plantio, obtendo-se maiores produtividades.

Com relação ao diâmetro da planta na entrelinha, verificou-se que o híbrido Sharon apresentou a maior média para esta característica, com $115,40 \mathrm{~cm}$, o que não diferiu estatisticamente dos híbridos Verona, TPX00123 e Veneza (112,77 $\mathrm{cm}, 111,17 \mathrm{~cm}$ e $107,90 \mathrm{~cm}$, respectivamente). Estes híbridos apresentaram grande desenvolvimento da planta, o que pode ter ocasionado competição entre as plantas da cultura.

Para o híbrido Snow-Flake, observou-se a menor média de diâmetro da planta na entrelinha, com 90,55 cm, o qual não diferiu estatisticamente dos híbridos First-Snow e Sarah $(97,75$ e 99,40 cm, respectivamente).

Vale ressaltar que a produção de uma cultura é o somatório de todas as interações planta-ambiente. A biomassa vegetal, seja como produto de interesse econômico ou do ponto de vista ecológico, é estritamente dependente do processo fotossintético. Portanto, plantas com maior desenvolvimento possuem maior área foliar e consequentemente dução com menor desenvolvimento das plantas. Portanto, cultivares de couveflor que apresentem bom peso médio de cabeça com pequeno desenvolvimento constituem boa alternativa ao produtor para garantir maior produtividade em função do adensamento e se tornar mais competitivo no mercado.

Para diâmetro do caule, observouse que os híbridos Veneza e TPX00123 apresentaram as maiores médias para esta característica, não diferindo dos híbridos Verona $(3,07 \mathrm{~cm})$, First-Snow $(2,99 \mathrm{~cm})$, Sharon $(2,97 \mathrm{~cm})$ e TPC00218 (2,89 cm). Os híbridos Snow-Flake e Sarah apresentaram as menores médias de diâmetro do caule, 2,81 e 2,82 cm, respectivamente, diferindo significativamente apenas dos híbridos Veneza e TPX 00123. É de se esperar que cultivares que apresentem maior diâmetro de caule também apresente maior peso de cabeça e consequentemente maior produtividade, pois há mais vasos de transporte para translocação de água, e fotoassimilidos. Além disso, caules mais espessos suportam cabeças mais pesadas.

Para precocidade média observou-se que o híbrido Verona foi o mais tardio, com 119 dias, não diferindo estatisticamente do híbrido Sharon (116 dias) sendo considerados, portanto, cultivares de ciclo longo. Este resultado difere dos do cultivares que apresentam boa pro-

Tabela 2. Médias da massa média da cabeça (MC), altura da cabeça (AC), diâmetro da cabeça (DC) e produtividade média estimada por hectare (PMEH), de híbridos de couve-flor de verão (means of weight, height and diameter of the head and estimated productivity per hectare, in eight hybrids of cauliflower of Summer). Jaboticabal, UNESP, 2007.

\begin{tabular}{lcccc}
\hline Híbridos & MC (kg) & AC (cm) & DC (cm) & $\begin{array}{c}\text { PMEH (t } \\
\left.\mathbf{h a}^{-1}\right)\end{array}$ \\
\hline Snow Flake & $0,73 \mathrm{c}$ & $10,03 \mathrm{~b}$ & $24,95 \mathrm{ab}$ & $14,56 \mathrm{c}$ \\
First Snow & $1,09 \mathrm{ab}$ & $12,84 \mathrm{a}$ & $23,55 \mathrm{~b}$ & $21,80 \mathrm{ab}$ \\
TPX 00123 & $1,16 \mathrm{a}$ & $12,13 \mathrm{a}$ & $24,37 \mathrm{ab}$ & $23,25 \mathrm{a}$ \\
TPC 00218 & $1,19 \mathrm{a}$ & $12,02 \mathrm{a}$ & $25,65 \mathrm{ab}$ & $23,76 \mathrm{a}$ \\
Sharon & $1,06 \mathrm{ab}$ & $12,22 \mathrm{a}$ & $26,37 \mathrm{a}$ & $21,25 \mathrm{ab}$ \\
Veneza & $0,97 \mathrm{~b}$ & $11,52 \mathrm{ab}$ & $23,80 \mathrm{~b}$ & $19,43 \mathrm{~b}$ \\
Verona & $1,12 \mathrm{ab}$ & $11,99 \mathrm{a}$ & $25,27 \mathrm{ab}$ & $22,43 \mathrm{ab}$ \\
Sarah & $1,11 \mathrm{ab}$ & $12,44 \mathrm{a}$ & $24,72 \mathrm{ab}$ & $22,30 \mathrm{ab}$ \\
\hline Teste F & $13,84 * *$ & $6,08 * *$ & $4,08 * *$ & $13,90 * *$ \\
\hline DMS (Tukey, 5\%) & 0,19 & 1,5842 & 2,2090 & 3,76 \\
\hline CV (\%) & 7,51 & 5,63 & 3,75 & 7,50 \\
\hline
\end{tabular}

Médias seguidas pela mesma letra na coluna não diferem entre si, pelo Teste de Tukey, a 5\% de probabilidade (means followed by the same letter in the column do not differ significantly, according to Tukey's test at 5\% level of probability). 
Tabela 3. Classificação das cabeças de oito híbridos de couve-flor de verão (classification of heads of eight hybrids of cauliflower for Summer). Jaboticabal, UNESP, 2007.

\begin{tabular}{lccc}
\hline \multirow{2}{*}{ Híbrido } & \multicolumn{3}{c}{ Classificação das cabeças } \\
\cline { 2 - 4 } & Classe & Categoria & Tonalidade \\
\hline Snow-Flake & 8 & extra & 0 \\
First-Snow & 8 & extra & 100 \\
TPS00123 & 8 & extra & 0 \\
TPC00218 & 8 & extra & 0 \\
Sharon & 8 & extra & 0 \\
Veneza & 8 & extra & 0 \\
Verona & 8 & extra & 0 \\
Sarah & 8 & extra & 0 \\
\hline
\end{tabular}

$8=$ diâmetro de cabeça maior que $230 \mathrm{~mm}$; extra= isentas de defeitos; $0=$ coloração creme de cabeça; $100=$ coloração branca de cabeça $(8=$ diameter of head over $230 \mathrm{~mm}$; extra= without defects; $0=$ cream coloration of head; $100=$ white coloration of head).

observados por Oliveira et al. (2007) que, avaliando a dinâmica de crescimento da cultura de couve-flor, verificaram que o híbrido Verona, aos 101 dias após a semeadura, atingiram o ponto de colheita. Esta diferença de precocidade se deve ao fato do experimento dos referidos autores ter sido conduzido no outono/inverno, época que é mais propicia para a cultura da couve-flor, o que consequentemente resultou num período menor entre a semeadura e a colheita.

Períodos prolongados de temperatura acima de $25^{\circ} \mathrm{C}$ podem retardar a formação da cabeça em plantas que se encontram em fase de crescimento vegetativo, enquanto que plantas com cabeças em formação podem reverter para crescimento vegetativo, reduzindo o tamanho das cabeças e causando desenvolvimento de folhas ou brácteas nos pedúnculos florais (University of California, 1987).

O híbrido Snow-Flake foi o mais precoce entre os oito híbridos avaliados, com ciclo de 95 dias. Os híbridos First-Snow, Sarah, Veneza, TPC00218 e TPX00123 não diferiram entre si, com respectivamente $107,108,108,109$ e 111 dias de ciclo, sendo consideradas cultivares de ciclo médio.

Na Tabela 2, são apresentadas as médias da massa das cabeças de couve-flor, altura das cabeças, diâmetro das cabeças e produtividade média estimada por hectare de oito híbridos de couve-flor de verão. Para todas as características avaliadas, foram observadas diferenças estatísticas significativas entre os híbri- dos avaliados.

Para massa das cabeças de couveflor, pode-se observar que os híbridos TPC00218 e TPX00123 apresentaram as maiores médias $(1,19 \mathrm{~kg}$ e $1,16 \mathrm{~kg}$, respectivamente), diferindo apenas dos híbridos Snow-Flake e Veneza, que apresentaram as menores médias para esta característica, com $0,73 \mathrm{~kg}$ e 0,97 $\mathrm{kg}$, respectivamente.

O híbrido Verona apresentou massa média de cabeça de $1,12 \mathrm{~kg}$. Este resultado difere do apresentado por Oliveira et al. (2007) que verificou para a cultivar Verona valor inferior ao do presente trabalho, $0,77 \mathrm{~kg}$ de massa de cabeça. Este fato pode estar relacionado à época de realização do experimento que aconteceu um ano antes, no período de $23 / 02 / 06$ a $05 / 06 / 06$, ao estado nutricional da cultura ou ao manejo adotado nos diferentes experimentos.

O híbrido Sharon apresentou massa média de cabeça de $1,06 \mathrm{~kg}$, não diferindo dos híbridos com maiores massas. Este valor foi superior ao encontrado por Kikuti (2006), que observou cabeças de $0,89 \mathrm{~kg}$ nesta cultivar. Esta diferença pode estar relacionada ao local de realização do experimento, desenvolvido em Piracicaba ou ao menor espaçamento adotado pelo referido autor $(0,7 \times 0,6 \mathrm{~m})$, podendo ter ocasionado maior competição entre as plantas da cultura prejudicando o desenvolvimento da cabeça.

Godoy \& Cardoso (2005), avaliando a produção de couve-flor cultivar Shiromaru II, observaram massa fresca da cabeça de $0,34 \mathrm{~kg}$. Observa-se que os valores encontrados no presente trabalho são superiores aos observados pelos autores acima citados. Este fato pode estar relacionado à diferença de cultivares utilizadas, ao local e época de realização dos experimentos, pois o experimento dos autores acima citados foi realizado em São Manuel-SP, de novembro a abril de 2001, período este que favorece a formação da parte vegetativa da planta.

Para diâmetro de cabeça verifica-se que o híbrido Sharon obteve a maior média, $\operatorname{com} 26,37 \mathrm{~cm}$, diferindo apenas do híbrido First Snow. Esta média é superior à apresentada por Kikuti (2006), que foi de 20,33 cm, em experimento realizado em Piracicaba com a cultivar Sharon. Isto pode estar relacionado à diferente época de realização do experimento, que foi de dezembro de 2004 a fevereiro de 2005, época esta que favorece o desenvolvimento da parte vegetativa da planta, e ainda ao espaçamento adotado, que no presente trabalho é superior $(0,5$ x 1,0 m). Os demais híbridos, TPC00218 $(25,65 \mathrm{~cm})$, Verona $(25,27 \mathrm{~cm})$, SnowFlake $(24,95 \mathrm{~cm})$, Sarah $(24,72 \mathrm{~cm})$ e TPX00123 $(24,37 \mathrm{~cm})$ não diferem estatisticamente do híbrido Sharon e não diferem entre si para esta característica. Vale destacar que todos os híbridos apresentaram diâmetro de cabeça superior ao mínimo exigido para comercialização, conforme o PROGRAMA HORTI \& FRUTI PADRÃO (1999). Oliveira et al. (2007) constataram para a cultivar Verona diâmetro de cabeça de 25,25 $\mathrm{cm}$, resultado semelhante ao observado neste trabalho.

Com relação à altura das cabeças de couve-flor, o híbrido Snow-Flake apresentou a menor altura, com $10,03 \mathrm{~cm}$, não diferindo apenas do híbrido Veneza, fato este que provavelmente está relacionado ao menor desenvolvimento da cabeça nesta cultivar. Esta característica, juntamente com o diâmetro da planta dão idéia do formato da cabeça.

Godoy \& Cardoso (2005) avaliando a produção de couve-flor cultivar Shiromaru II, observaram diâmetro de cabeça de $13,7 \mathrm{~cm}$. Observa-se que os valores encontrados na presente pesquisa são superiores aos observados pelos autores acima citados. Este fato pode estar relacionado à diferença de cultivares 
utilizadas ou ao local e época de realização do experimento (São Manuel-SP), de novembro a abril de 2001.

Com relação à produtividade média estimada por hectare, os híbridos TPC00218 e TPX00123 apresentaram as maiores médias, com 23,76 e 23,25 $\mathrm{t} \mathrm{ha}^{-1}$, diferindo apenas dos híbridos Veneza e Snow-Flake. A cultivar Verona apresentou média de produtividade de $22,43 \mathrm{t} \mathrm{ha}^{-1}$. Este resultado é superior ao apresentado por Oliveira et al. (2007) que constataram para a cultivar Verona, produtividade estimada de 15,47 t $\mathrm{ha}^{-1}$. O híbrido Snow-Flake apresentou a menor média para esta característica (14,56 t ha-1).

Para o híbrido Sharon constatouse produtividade estimada de 21,25 t, resultado semelhante ao apresentado por Kikuti (2006) (21,3 t ha-1). Os espaçamentos utilizados foram diferentes, sendo o da presente pesquisa de 1,0 m entrelinhas e $0,5 \mathrm{~m}$ entre plantas e o utilizado por Kikuti (2006) de 0,7 m entre plantas e 0,6 m entrelinhas. Dessa forma, o número de cabeças por hectare é menor no presente trabalho, porém com maiores massas o que compensa a produtividade semelhante.

Pizetta et al. (2005) avaliando o desenvolvimento da couve-flor híbrido Júlia, com diferentes teores de boro aplicados no solo, verificaram que a maior produtividade foi de 29,6 $\mathrm{t} \mathrm{ha}^{-1}$, resultado superior a presente pesquisa. Este fato pode ser explicado pela diferença de cultivar utilizada e pela quantidade de boro aplicada.

Trani \& Raij (1997) consideram como boa produtividade de couve-flor uma faixa de 8 a $16 \mathrm{t} \mathrm{ha}^{-1}$. No presente trabalho verificaram-se produtividades de 14,5 a 23,7 $\mathrm{t} \mathrm{ha}^{-1}$. Sendo assim, todos os híbridos avaliados estão dentro ou acima da faixa considerada boa pelos referidos autores. Esta superioridade na produção de couve-flor, em grande parte, deve-se a cultivares mais produtivas desenvolvidas nos últimos anos.

O híbrido com menor desenvolvimento de plantas, o First-Snow, apresentou boa produtividade, não diferindo estatisticamente dos híbridos de maior produtividade, TPX00123 e TPC00218, indicando que é uma boa escolha para o produtor, pois permite adensamento do plantio, obtendo-se maior produtividade.

Para a classificação das cabeças de couve-flor, foram levados em consideração diâmetro transversal, categoria (danos) e tonalidade (coloração) da cabeça, seguindo recomendações do Programa Horti \& Fruti Padrão (1999).

A Tabela 3 contém a classificação das cabeças dos oito híbridos de couve-flor de verão, avaliados neste experimento. Todos estes híbridos foram incluídos na classe 8 , por possuírem diâmetro de cabeça superior a $230 \mathrm{~mm}$. Com relação à categoria (danos), todas as cabeças dos híbridos foram classificadas como extra, isentas de defeitos.

Quanto à tonalidade, todos os híbridos foram classificados como 0 por apresentarem coloração creme de cabeça, exceto o híbrido First-Snow que foi classificado como 100, por apresentar coloração branca de cabeça.

A produtividade de couve-flor para os híbridos avaliados foi expressiva, porém há uma carência de informações na literatura sobre os híbridos testados e sobre comparação entre cultivares. Portanto, fazem-se necessários novos estudos sobre o assunto, como comparação entre as cultivares, diferentes espaçamentos, uso de cobertura de solo, dentre outros.

Com base nos resultados obtidos no cultivo de couve-flor de verão em campo aberto, para as condições edafoclimáticas de Jaboticabal, é possível concluir que os híbridos TPC00218 e TPX00123 mostraram-se promissores, com produtividades comerciais de 23,8 e 23,2 t ha $^{-1}$, respectivamente. O híbrido First-Snow possui baixo desenvolvimento de planta, e boa produtividade. O híbrido Snow-Flake, por apresentar menor produtividade, não é recomendado para plantio na região de Jaboticabal. Todos os híbridos testados apresentaram produção classificada na categoria extra e na classe 8 (maiores que $230 \mathrm{~mm}$ ).

\section{REFERÊNCIAS}

ANDRIOLI I; CENTURION JF. 1999. Levantamento detalhado dos solos da Faculdade de Ciências Agrárias e Veterinárias de Jaboticabal. In:CONGRESSO BRASILEIRO DE CIÊNCIA DO SOLO, 27. Anais... Brasília:
SBCS, $32 \mathrm{p}$.

BLANCO MCSG; GROPPO GA; NETO JT. 1997. Couve-flor (Brassica oleracea var. botrytis L.). Campinas: Coordenadoria de Assistência Técnica Integral, v. 2, p. 57-61.

ESTAÇÃO AGROCLIMATOLÓGICA. 2007. Resenha metereológica do período 1971 2000. Jaboticabal: Departamento de Ciências Exatas, FCAV-UNESP. 2003. Disponível em : www.fcav.unesp.br/departamento/ exatas/estação/resenha, Acessado em 30 agosto de 2007.

FILGUEIRA FAR. 2003. Novo manual de olericultura. Viçosa: UFV, p. 275-280.

FONTES PCR. 2005. Olericultura: teoria e prática. Viçosa: UFV, p. 3-13.

FREITAS, JA. 1995.. Avaliação qualitativa de híbridos experimentais de couve-flor de verão Brássicas oleracea L. var. botrytis L. Ciência e Prática 19: 135-138.

GODOY MC; CARDOSO AII. 2005. Produtividade da couve-flor em função da idade de transplantio das mudas produzidas e tamanhos de células na bandeja. Horticultura Brasileira 23: 837-840.

KIKUTI ALP. 2006. Avaliação do potencial fisiológico, métodos de condicionamento e desempenho de sementes de couve-flor (Brassica oleracea L. var. botrytis) durante o armazenamento e em campo. Piracicaba: ESALQ. 155p (Tese doutorado).

MAY A; TIVELLI SW; VARGAS PF; SAMRA AG; SACCONI LV; PINHEIRO MQ. 2007. A cultura da couve-flor. Campinas: IAC (Boletim Técnico, 200). Disponível em: http://www.iac. sp.gov.br/Btonline/Publiconline.asp. Acessado em: 8 ago. 2007.

OLIVEIRA SF; CASTOLDI R; VARGAS PF; CHARLO HCO; BRAZ LT. 2007. Crescimento, distribuição de matéria seca e produtividade de couve-flor 'Verona'. In: CONGRESSO BRASILEIRO DE OLERICULTURA, 47. Anais eletrônicos... Porto Seguro: SOB. Disponível em www.abhorticultura. com.br/Eventosx/trabalhos/ev_1/ A244_T274_Comp.pdf. Acessado em 15 de janeiro de 2008 .

PIZETTA LC; FERREIRA ME; CRUZ MCP; BARBOSA JC. 2005. Resposta de brócolis, couve-flor e repolho à adubação com boro em solo arenoso. Horticultura Brasileira 23: 51-56.

PROGRAMA HORTI \& FRUTI PADRÃO. Classificação da couve-flor. 1999. Disponível em http//www.hortibrasil.org.br/classificacao/ couveflor/couveflor.html. Acessado em 24 de agosto de 2007.

TAVARES CA. 2007. Couve-flor: técnica certa. Pelotas-RS, 2000. Disponível em: http://www. grupocultivar.com.br/info/contato.asp?id=72. Acessado em 23 de julho de 2007.

TRANI PE; RAIJ B. 1997. Hortaliças. In: RAIJ B; CANTARELLAH; QUAGGIO JA; FURLANI AMC. Recomendações de adubação e calagem para o Estado de São Paulo. Campinas: IAC, p.157-164.

UNIVERSITY OF CALIFORNIA. 1987. Integrated pest management for cole crops and lettuce. Berkeley: Division of Agriculture and Natural Resources, 112p. 